\title{
Chinese and Indian Stock Markets: Linkages and Interdependencies
}

\author{
Karthigai Prakasam Chellaswamy ${ }^{1}$, Natchimuthu N. ${ }^{1} \&$ Muhammadriyaj Faniband ${ }^{1}$ \\ ${ }^{1}$ Department of Commerce, CHRIST (Deemed to be University), Bengaluru, India \\ Correspondence: Karthigai Prakasam Chellaswamy, Department of Commerce, CHRIST (Deemed to be University), \\ Bengaluru- 560029, India.
}

Received: October 25, 2020

Accepted: December 23, 2020

Online Published: February 9, 2021

doi:10.5430/rwe.v12n2p228

URL: https://doi.org/10.5430/rwe.v12n2p228

This study is a part of the Major Research Project funded by a grant from the 'Centre for Research-Projects, CHRIST (Deemed to be University)', Bengaluru, India.

\begin{abstract}
This paper examines the stock market linkages and interdependencies between China and India. We use the quantile regression approach as an alternative to Ordinary Least Squares estimation due to its flexibleness and robustness. Our results of the entire time period reveal the influence of Chinese CPI and ER on Nifty returns is not the same across the different quantiles. However, Chinese IR has no impact on Nifty returns. Further, Indian CPI has a negligible effect on SSE returns. In contrast, IR and ER do not affect SSE returns. This study also observes that the dependence structure between CPI and SSE returns indicates a negligible change post-recession period. However, the dependence structure between IR, ER, and SSE returns has not changed after the recession. Further, a significantly small change is found in the dependence structure between Chinese macroeconomic variables and Nifty returns post-recession.
\end{abstract}

Keywords: stock market linkages, stock market interdependencies, macroeconomic factors, Nifty, Shanghai, stock exchange composite index, quantile regression

\section{Introduction}

The economic development of China is frequently compared to that of India. The trade of these two large emerging economies are heterogeneous (Bussière \& Mehl, 2008). The striking growth of China's economy in the past few decades helped the Chinese stock market to come forth as one of the largest stock markets in the world (Ye, 2014). China and India have some common key factors for instance huge geographical area, big working class, encouraging government policies, and middle-class growth which are vital in keeping long-term economic growth and also have the power to turn large economies (Lao \& Singh, 2011).

The selection of China and India is motivated by the fact that these two emerging economies have different economic environments. China and India are the $2^{\text {nd }}$ and $5^{\text {th }}$ largest economies of the world respectively (International Monetary Fund's World Economic Outlook, October 2019). However, India has lost its title of the fastest growing economy to China in the year 2019 as its economic growth slowed compared to China's growth. These two economies have been experiencing rapid growth over the past couple of decades, but an unreassuringly combination of development challenges and international trade tensions introduces a threat to their economic outlook. India is on the path to catch Germany as the fourth-largest economy by 2026 (Aldrick, 2019). Hence, it becomes crucial for the investors to understand the linkages of fundamentals of China's economy with the Indian stock market and vice versa before any investment decision.

The movement in stock prices does not only depend on a firm's fundamentals but also depends upon the level of economic growth in the country and its integration with the world economy (Sengupta, Dutta, \& Dutta, 2019). From an investment perspective, investors take into account a progressive macroeconomic environment because it helps companies to expand their business and increase profitability. Therefore, it highlights the significance to investigate the interaction between Chinese and Indian stock markets to the large extent. In this paper, we analyse the impact of the Chinese Consumer Price Index (CPI), Interest Rate (IR), and Exchange Rate (ER) on Nifty 50 returns and Indian CPI, IR, and ER on the Shanghai Stock Exchange (SSE) Composite returns.

More precisely, this paper addresses the following unanswered questions. Do China's macroeconomic factors show the 
existence of dependence with Nifty returns? Similarly, Do India's macroeconomic variables affect SSE returns? Is the dependence structure between macroeconomic variables and SSE and NSE returns symmetric or asymmetric? Has the global financial crisis changed the dependence structure?

The significant contribution of this paper is that to the best of found knowledge, this is the first attempt to find the linkages and dependencies between Chinese and Indian stock markets using the QR approach.

The remainder of this paper is organized as follows. Section two presents a review of relevant literature. Section three shows methodology. Section four illustrates data and summary statistics. Section five reveals the empirical results. Finally, section six indicates the paper's conclusion and recommendations.

\section{Review of Literature}

A wide range of studies is conducted in the different parts of the globe at different points in time and under various conditions on the influence of macroeconomic factors on stock markets of China and India. (Sharma, Mahendru, \& Singh, 2013) study the interlinkages between stock markets of Brazil, Russia, India, China, and South Africa (BRICS). The study showed that these stock markets are affected by each other, but not to a great extent. (Lao \& Singh, 2011) show that the herding behaviour exists in both the Shanghai A-Share index and SENSEX. (Hosseini, Ahmad, \& Lai, 2011) detect both short and long-term associative relations between macroeconomic variables and stock market indices of China and India. (Chen, 2007) finds that hotel stock returns in China are affected by macro factors and Non-macro events i.e. financial crisis. (Yang, Cheng, Huang, \& Wang, 2019) investigate systemic risk in the Chinese stock market from 2007 to 2018. The top contributor to systemic risk is the information technology sector. (Singhania \& Girish, 2015) use event study method and find that various macroeconomic events have negative effects on returns of the SSE Composite Index. (Johansson, 2010) discover that level integration of Chinese stock market has increased with several major financial markets during the 2008 global financial crisis in particular. (Alshammari, 2020) notice a strong long-term relationship among the Gulf Cooperation Council stock exchanges and causality tests support the short-term relationships. Further, (Panda \& Thiripalraju, 2020) finds that BRICS countries are a good destination for investors.

An abundance of studies have been conducted in the Indian context, (Patel, 2017) analyse the co-movement among 14 stock markets and found that BSE returns are dependent on Bovespa, Financial Times Stock Exchange - 100, and Mexico Stock Exchange only. The study also found a long-run relationship. (Sengupta et al., 2019 \& Das \& Megaravalli, 2017) also, confirm that macroeconomic factors explain the Nifty. (Kaur \& Arora, 2018) analyse the interdependence among the various markets in India such as stock, currency, government bonds, and commodity markets. (Faniband \& Marulkar, 2020) confirm the existence of long-run cointegration between three numbers of quarterly results (total income, net profit, and EPS) and share prices.

In the other context, considerable research has also been done on linkages of Chinese and Indian stock markets with developed and other emerging markets include, (Pani, Bhatt, \& Himatsingka, 2019) show that Asian stock markets have a better correlation with Sensex post-2000. (Bhattacharyya et al., 2017) study how the stock market volatility in the Southeast Asian emerging markets are affected by foreign portfolio investment during the global financial crisis and this effect is compared with India. (Jarrett, Klein, \& Kyper, 2013) examine the time series characteristics of Tokyo, Hong Kong, London, and New York equity markets. (Daboussi \& Majoul, 2014) confirm that the U.S transmitted its business cycles and economic recession effect to India and Asia and Latin America emerging economies. (Dasgupta, 2014) finds interdependencies and dynamic linkages of India with the BRIC stock markets.

Considerable research has also been done on the determinants of stock market returns using the QR method. (Wang et al., 2011) confirm the long-run association between political behavior and stock market returns in Taiwan. (Tsai, 2012) uses the six Asian countries' data and finds a negative association between foreign exchange markets and stock. (Ni, Wang, \& Xue, 2015) investigate how the Chinese A-share returns based on monthly data are nonlinearly influenced by investor sentiment. (Allen, Singh, \& Powell, 2013) utilize this method to analyse risk and return distributions and examine the pattern of the book to market ratios and beta, two extensively employed asset pricing factors. (Mishra \& Debasish, 2019 \& Zhu, Guo, You, \& Xu, 2016) employ the same method to study the dependence between crude oil prices and stock market returns.

Past studies have ignored the interlinkages between China and India's stock market. Further, previous studies have generally used Ordinary Least Square (OLS) or other models to address such issues. In contrast, we apply the QR model. This methodology allows us a more flexible approach to capture a more comprehensive picture of the stock price behaviour.

\section{Research Methodology}

Regression analysis is useful to find the association between a dependent variable and explanatory variables. The QR is 
proposed by Koenker \&Bassett, (1978). An extension of linear regression is QR. Linearity, independence or normality, homoscedasticity are the condition to use linear regression. QR is used when the above conditions are not met. Regular linear regression considers least squares to calculate the conditional mean. In contrast, the conditional median of the target is estimated by QR. QR is not limited just to find the median, but any quantile can be calculated for a particular value in the features variables. In this context, a better result of the impact of Chinese macroeconomic factors on Nifty returns and Indian macroeconomic factors on SSE returns with a quantile ranging from 0.1 to 0.9 . The full distribution of the SSE and Nifty conditional on the Indian and Chinese macroeconomic factors respectively can be brought out using QR.

The QR model of Koenker \& Bassett (1978) can be written as

$$
y_{i}=x_{i}^{\prime} \beta_{\theta}+u_{\theta i} \text { with } Q_{\theta}\left(y_{t} \mid x_{t}\right)=x_{t}^{\prime} \beta_{\theta}
$$

Where $\mathrm{xt}^{\prime}$ indicates a vector of regressors, denotes the vector of parameters to be estimated and $\mathrm{u} \theta \mathrm{i}$ represents a vector of residuals. Qxt denotes the ${ }^{\text {th }}$ conditional quantile of yi granted xi'.

The approximation of is supported on the following optimisation problem:

$$
\left\{\sum_{t: y t>x_{t}^{\prime} \beta} \theta\left|y_{i}-x^{\prime}{ }_{i} \beta\right|+\sum_{t: y t>x_{t}^{\prime} \beta}(1-\theta)\left|y_{i}-x_{i}^{\prime} \beta\right|\right\}
$$

The optimisation problem can be figured out by applying a linear programming representation via the simplex algorithm or the generalised method of moments framework (Brooks, 2014). The median regression is received by placing $\theta=0.5$. Other quantiles of the conditional distribution can be found through variations of $\theta$. The sound practical relationship of selected explanatory variables across the total conditional Chinese and Indian stock market distribution is expressed through The results for the $0.1,0.2,0.3,0.4,0.5,0.6,0.7,0.8$, and 0.9 quantiles. In this paper, the bootstrap method given by Buchinsky (1995) is applied to hold approximations of the standard errors for the coefficients in quantile regression. Moreover, it is effective for a comparatively small sample size.

The following equations are the basic models of this empirical study:

$$
\text { SSE Returns }=\alpha+\beta_{1} \text { INDCPI }+\beta_{2} \text { INDIR }+\beta_{3} \text { INDER }+\varepsilon
$$

Where, INDCPI, INDIR, and INDER indicate Consumer Price Index, Interest Rate and Exchange Rate of India respectively and cis a random error.

$$
\text { Nifty Returns }=\mathrm{a}+\beta_{4} \mathrm{CHCPI}+\beta_{5} \mathrm{CHIR}+\beta_{6} \mathrm{CHER}+\mu
$$

Where CHCPI, CHIR, and CHER denote Consumer Price Index, Interest Rate, and Exchange Rate of China respectively and $\mu$ is a random error.

\section{Data and Summary Statistics}

This paper empirically examines the dependence structure between the macroeconomic factors and stock markets with regards to China and India over the monthly period from January 1998 to December 2018. The gap between SSE and Nifty returns is huge in the pre-recession and recession periods than in the post-recession. However, Nifty returns experienced a drastic fall during the recession period in comparison with SSE as shown in Figure 1. Therefore, these data are divided into two sample periods that is pre-recession and recession periods from 1998-2008 and the post-recession periods from 2009 to 2018. Since higher volatility can be experienced in daily data than weekly data; in turn, higher volatility in weekly data than monthly data, we prefer monthly frequency to daily or weekly. Chinese and Indian macroeconomic factors include (i) Consumer Price Index; (ii) Interest Rates; it is less than 24 Hours Call Money/Interbank Rate and (iii) Exchange Rate. In this paper, log-returns of the SSE and Nifty index are taken into account. The SSE and Nifty data are captured from the website of Yahoo Finance. FRED database is used to obtain the data of the CPI, IR, and ER of both countries. 


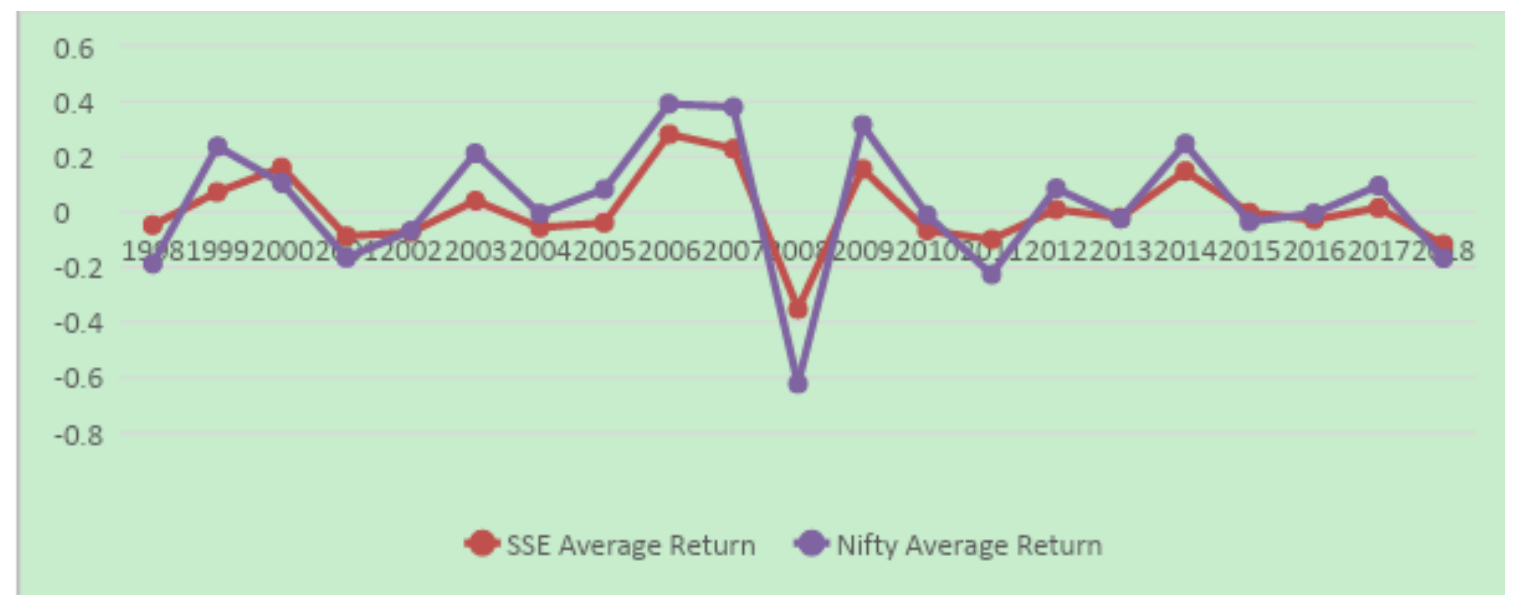

Figure 1. Average stock returns of SSE and Nifty

Inflation, interest rates, and exchange rates are the major macroeconomic elements that affect stock market returns (see, Das \& Megaravalli, 2017; Pal \& Mittal, 2011; Sengupta et al., 2019; Jareño, Ferrer, \& Miroslavova, 2016).

Finally, the null hypothesis of a unit root is tested applying conventional Augmented Dickey and Fuller (ADF) and Phillips and Perron (PP) statistics. We find that SSE and Nifty returns, Chinese and Indian IRs have no unit root. However, Chinese and Indian CPI and ER have a unit root. We made these variables stationary by taking the first difference. The median value of all the variables found to be less than the mean. Hence, these variables are skewed to the right. All the explanatory variables (except SSE and Nifty returns and Chinese IR) show a Kurtosis value less than the reference value of the normal distribution (i.e. equal to 3). It indicates that there are lighter tails than a normal distribution (less in the tails). Therefore, Jarque-Bera (JB) test results show that all the variables are not normally distributed (Table 1).

Table 1. Descriptive statistics and unit root tests

\begin{tabular}{lrrrrrrrrrr}
\hline & Mean & Median & \multicolumn{1}{c}{ Max. } & Min. & Std. Dev. & Skewness & Kurtosis & JB & ADF & PP \\
\hline SSE & 0.121 & 0.060 & 18.364 & -22.059 & 4.088 & -0.152 & 11.045 & $680.489^{\cdots \cdots}$ & $-12.012^{\cdots \cdots}$ & $-11.934^{\cdots \cdots}$ \\
\hline Nifty & 0.541 & 0.150 & 18.146 & -9.749 & 2.968 & 1.375 & 11.790 & $890.673^{\cdots \cdots}$ & $-12.640^{\cdots \cdots}$ & $-12.690^{\cdots \cdots}$ \\
\hline CH CPI & 84.743 & 84.080 & 106.800 & 68.629 & 12.543 & 0.268 & 1.550 & $25.074^{\cdots \cdots}$ & 0.137 & 1.165 \\
\hline IND CPI & 64.356 & 54.128 & 115.524 & 31.508 & 26.741 & 0.518 & 1.761 & $27.375^{\cdots \cdots}$ & 1.275 & 3.030 \\
\hline CH IR & 3.292 & 3.240 & 8.550 & 2.700 & 0.781 & 3.798 & 21.479 & $4191.271^{\cdots \cdots}$ & $-8.410^{\cdots \cdots}$ & $-8.967 \cdots$ \\
\hline IND IR & 7.048 & 6.500 & 11.000 & 6.000 & 1.256 & 0.924 & 2.659 & $37.059^{\cdots \cdots}$ & $-2.915^{\cdots \cdots}$ & $-3.198^{\cdots \cdots}$ \\
\hline CH ER & 7.169 & 6.897 & 8.310 & 6.051 & 0.749 & 0.126 & 1.512 & $23.900^{\cdots \cdots}$ & -1.073 & -1.908 \\
\hline IND ER & 48.979 & 45.477 & 70.363 & 35.810 & 8.684 & 0.812 & 2.312 & $32.678^{\cdots \cdots}$ & -0.722 & -1.621 \\
\hline
\end{tabular}

$* * \mathrm{p}<0.05$ and $* * * \mathrm{p}<0.01$.

Note: $\mathrm{CH}$ denotes China and IND indicates India

Table 2. Quantile regression estimates for SSE during 1998-2008

\begin{tabular}{lccccccccc}
\hline & $\mathbf{0 . 1}$ & $\mathbf{0 . 2}$ & $\mathbf{0 . 3}$ & $\mathbf{0 . 4}$ & $\mathbf{0 . 5}$ & $\mathbf{0 . 6}$ & $\mathbf{0 . 7}$ & $\mathbf{0 . 8}$ & $\mathbf{0 . 9}$ \\
\hline \multirow{2}{*}{$\boldsymbol{\alpha}$} & 2.008 & 2.610 & .209 & 1.206 & .917 & 1.596 & .772 & -.202 & -1.206 \\
& $(0.317)$ & $(0.182)$ & $(0.900)$ & $(0.408)$ & $(0.424)$ & $(0.173)$ & $(0.508)$ & $(0.920)$ & $(0.734)$ \\
\hline \multirow{2}{*}{ INDCPI } & $-.046^{* *}$ & $-.036^{* *}$ & -.004 & -.002 & -.004 & -.007 & .002 & .012 & .034 \\
& $(0.003)$ & $(0.018)$ & $(0.760)$ & $(0.877)$ & $(0.640)$ & $(0.414)$ & $(0.814)$ & $(0.456)$ & $(0.223)$ \\
\hline
\end{tabular}




\begin{tabular}{cccccccccc}
\hline \multirow{2}{*}{ INDIR } & -.104 & -.102 & -.015 & -.037 & -.036 & -.048 & -.012 & .027 & .080 \\
& $(0.229)$ & $(0.226)$ & $(0.832)$ & $(0.557)$ & $(0.466)$ & $(0.338)$ & $(0.813)$ & $(0.751)$ & $(0.602)$ \\
\hline \multirow{2}{*}{ INDER } & .005 & -.016 & -.0023 & -.022 & -.011 & -.020 & -.015 & -.005 & -.008 \\
& $(0.832)$ & $(0.501)$ & $(0.909)$ & $(0.228)$ & $(0.451)$ & $(0.160)$ & $(0.308)$ & $(0.835)$ & $(0.858)$
\end{tabular}

$* \mathrm{p}<0.10, * * \mathrm{p}<0.05$ and $* * * \mathrm{p}<0.01$.

Table 3. Quantile regression estimates for Nifty during 1998-2008

\begin{tabular}{lccccccccc}
\hline & $\mathbf{0 . 1}$ & $\mathbf{0 . 2}$ & $\mathbf{0 . 3}$ & $\mathbf{0 . 4}$ & $\mathbf{0 . 5}$ & $\mathbf{0 . 6}$ & $\mathbf{0 . 7}$ & $\mathbf{0 . 8}$ & $\mathbf{0 . 9}$ \\
\hline \multirow{2}{*}{$\boldsymbol{\alpha}$} & -4.908 & -1.863 & -.989 & -.516 & -.289 & -.345 & .141 & -.025 & .625 \\
& $(0.113)$ & $(0.513)$ & $(0.715)$ & $(0.819)$ & $(0.873)$ & $(0.787)$ & $(0.917)$ & $(0.986)$ & $(0.765)$ \\
\hline \multirow{2}{*}{ CHCPI } & .021 & .008 & .005 & .001 & .005 & .004 & -.002 & -.002 & -.005 \\
& $(0.332)$ & $(0.677)$ & $(0.790)$ & $(0.959)$ & $(0.683)$ & $(0.628)$ & $(0.819)$ & $(0.831)$ & $(0.731)$ \\
\hline \multirow{2}{*}{ CHIR } & -.091 & -.069 & -.057 & -.070 & $-.074 * *$ & $-.082^{* * *}$ & $-.073^{* * *}$ & -.021 & .001 \\
& $(0.139)$ & $(0.225)$ & $(0.286)$ & $(0.124)$ & $(0.041)$ & $(0.002)$ & $(0.007)$ & $(0.441)$ & $(0.978)$ \\
\hline \multirow{2}{*}{ CHER } & $.417 *$ & .157 & .093 & .093 & .033 & .058 & .064 & .069 & .015 \\
& $(0.052)$ & $(0.427)$ & $(0.619)$ & $(0.551)$ & $(0.791)$ & $(0.511)$ & $(0.490)$ & $(0.468)$ & $(0.916)$ \\
& & & & & & & & &
\end{tabular}

${ }^{*} \mathrm{p}<0.10,{ }^{* *} \mathrm{p}<0.05$ and $* * * \mathrm{p}<0.01$.

Table 4. Quantile regression estimates for SSE during 2009-2018

\begin{tabular}{lccccccccc}
\hline & $\mathbf{0 . 1}$ & $\mathbf{0 . 2}$ & $\mathbf{0 . 3}$ & $\mathbf{0 . 4}$ & $\mathbf{0 . 5}$ & $\mathbf{0 . 6}$ & $\mathbf{0 . 7}$ & $\mathbf{0 . 8}$ & $\mathbf{0 . 9}$ \\
\hline \multirow{2}{*}{$\boldsymbol{\alpha}$} & -5.122 & $-7.708^{*}$ & -4.078 & -4.307 &.-2.064 & 1.652 & 1.599 & 1.440 & .215 \\
& $(0.713)$ & $(0.097)$ & $(0.417)$ & $(0.415)$ & $(0.689)$ & $(0.711)$ & $(0.747)$ & $(0.816)$ & $(0.985)$ \\
\hline \multirow{2}{*}{ INDCPI } & .112 & .112 & .039 & -.083 & -.028 & -.007 & $-.163^{*}$ & $-.218^{*}$ & -.220 \\
& $(0.657)$ & $(0.178)$ & $(0.666)$ & $(0.385)$ & $(0.760)$ & $(0.414)$ & $(0.069)$ & $(0.053)$ & $(0.299)$ \\
\hline \multirow{2}{*}{ INDIR } & .404 & .562 & .259 & .273 & .296 & -.048 & .273 & .742 & 1.511 \\
& $(0.781)$ & $(0.243)$ & $(0.620)$ & $(0.619)$ & $(0.581)$ & $(0.338)$ & $(0.595)$ & $(0.251)$ & $(0.216)$ \\
\hline \multirow{2}{*}{ INDER } & -.241 & -.194 & -.072 & .162 & .058 & -.020 & .250 & .309 & .266 \\
& $(0.656)$ & $(0.280)$ & $(0.711)$ & $(0.431)$ & $(0.774)$ & $(0.160)$ & $(0.194)$ & $(0.201)$ & $(0.558)$ \\
\hline
\end{tabular}

${ }^{*} \mathrm{p}<0.10, * * \mathrm{p}<0.05$ and ${ }^{* * *} \mathrm{p}<0.01$

Table 5. Quantile regression estimates for Nifty during 2009-2018

\begin{tabular}{lccccccccc}
\hline & $\mathbf{0 . 1}$ & $\mathbf{0 . 2}$ & $\mathbf{0 . 3}$ & $\mathbf{0 . 4}$ & $\mathbf{0 . 5}$ & $\mathbf{0 . 6}$ & $\mathbf{0 . 7}$ & $\mathbf{0 . 8}$ & $\mathbf{0 . 9}$ \\
\hline \multirow{2}{*}{$\boldsymbol{\alpha}$} & 62.506 & 21.965 & -5.069 & 9.206 & 15.825 & 10.603 & 33.594 & 60.030 & 81.786 \\
& $(0.410)$ & $(0.670)$ & $(0.894)$ & $(0.782)$ & $(0.636)$ & $(0.741)$ & $(0.260)$ & $(0.136)$ & $(0.247)$ \\
\hline \multirow{2}{*}{ CHCPI } & -.066 & -.020 & .050 & .027 & -.037 & -.055 & $-.111^{*}$ & -.122 & $-.353^{* *}$ \\
& $(0.676)$ & $(0.851)$ & $(0.532)$ & $(0.698)$ & $(0.591)$ & $(0.412)$ & $(0.076)$ & $(0.145)$ & $(0.018)$ \\
\hline \multirow{2}{*}{ CHIR } & -10.064 & -4.167 & -1.943 & -5.263 & -3.338 & -.767 & -3.600 & -7.014 & -7.171 \\
& $(0.286)$ & $(0.515)$ & $(0.681)$ & $(0.204)$ & $(0.421)$ & $(0.847)$ & $(0.331)$ & $(0.160)$ & $(0.413)$ \\
\hline \multirow{2}{*}{ CHER } & -4.600 & -1.385 & .833 & .677 & -.097 & -.127 & -1.356 & -3.520 & -3.053 \\
& $(0.515)$ & $(0.773)$ & $(0.814)$ & $(0.827)$ & $(0.975)$ & $(0.966)$ & $(0.625)$ & $(0.347)$ & $(0.642)$
\end{tabular}

$* \mathrm{p}<0.10, * * \mathrm{p}<0.05$ and $* * \mathrm{p}<0.01$. 
Table 6. Quantile regression estimates for SSE during 1998-2018

\begin{tabular}{lccccccccc}
\hline & $\mathbf{0 . 1}$ & $\mathbf{0 . 2}$ & $\mathbf{0 . 3}$ & $\mathbf{0 . 4}$ & $\mathbf{0 . 5}$ & $\mathbf{0 . 6}$ & $\mathbf{0 . 7}$ & $\mathbf{0 . 8}$ & $\mathbf{0 . 9}$ \\
\hline \multirow{2}{*}{ A } & 1.727 & 3.551 & 2.098 & 1.387 & -.744 & -1.675 & -2.083 & $-3.613^{*}$ & -4.499 \\
& $(0.752)$ & $(0.113)$ & $(0.261)$ & $(0.458)$ & $(0.625)$ & $(0.221)$ & $(0.184)$ & $(0.067)$ & $(0.324)$ \\
\hline \multirow{2}{*}{ INDCPI } & $-.123^{* *}$ & $-.064^{* * *}$ & $-.039^{* *}$ & -.003 & .009 & $.023^{*}$ & $.035^{* *}$ & $.062^{* * *}$ & $.101^{* *}$ \\
& $(0.017)$ & $(0.002)$ & $(0.026)$ & $(0.843)$ & $(0.509)$ & $(0.081)$ & $(0.019)$ & $(0.001)$ & $(0.019)$ \\
\hline \multirow{2}{*}{ INDIR } & -.142 & -.163 & -.108 & -.037 & .040 & .126 & .144 & .253 & .270 \\
& $(0.777)$ & $(0.425)$ & $(0.528)$ & $(0.830)$ & $(0.776)$ & $(0.314)$ & $(0.318)$ & $(0.160)$ & $(0.518)$ \\
\hline \multirow{2}{*}{ INDER } & .083 & -.003 & .001 & -.024 & .002 & -.001 & -.003 & -.007 & -.021 \\
& $(0.605)$ & $(0.965)$ & $(0.990)$ & $(0.662)$ & $(0.957)$ & $(0.987)$ & $(0.955)$ & $(0.902)$ & $(0.879)$ \\
\hline
\end{tabular}

$* \mathrm{p}<0.10, * * \mathrm{p}<0.05$ and $* * * \mathrm{p}<0.01$.

Table 7. Quantile regression estimates for Nifty during 1998-2018

\begin{tabular}{lccccccccc}
\hline & $\mathbf{0 . 1}$ & $\mathbf{0 . 2}$ & $\mathbf{0 . 3}$ & $\mathbf{0 . 4}$ & $\mathbf{0 . 5}$ & $\mathbf{0 . 6}$ & $\mathbf{0 . 7}$ & $\mathbf{0 . 8}$ & $\mathbf{0 . 9}$ \\
\hline \multirow{2}{*}{$\boldsymbol{\alpha}$} & 1.640 & -.055 & .322 & -4.056 & -5.123 & -2.550 & 1.002 & 2.482 & 16.137 \\
& $(0.903)$ & $(0.992)$ & $(0.950)$ & $(0.433)$ & $(0.287)$ & $(0.593)$ & $(0.851)$ & $(0.698)$ & $(0.152)$ \\
\hline \multirow{2}{*}{ CHCPI } & -.086 & -.037 & -.025 & .027 & $.052^{* *}$ & $.054^{* *}$ & $.052^{*}$ & $.068^{* *}$ & .024 \\
& $(0.198)$ & $(0.208)$ & $(0.322)$ & $(0.295)$ & $(0.031)$ & $(0.024)$ & $(0.053)$ & $(0.033)$ & $(0.664)$ \\
\hline \multirow{2}{*}{ CHIR } & -.044 & -.013 & -.047 & -.064 & -.079 & -.062 & -.050 & -.011 & -.101 \\
& $(0.933)$ & $(0.956)$ & $(0.815)$ & $(0.750)$ & $(0.673)$ & $(0.738)$ & $(0.809)$ & $(0.965)$ & $(0.818)$ \\
\hline \multirow{2}{*}{ CHER } & .521 & .317 & .198 & .296 & .220 & -.124 & -.541 & $-.875^{*}$ & $-2.087^{* *}$ \\
& $(0.638)$ & $(0.511)$ & $(0.640)$ & $(0.486)$ & $(0.577)$ & $(0.752)$ & $(0.217)$ & $(0.097)$ & $(0.025)$ \\
\hline
\end{tabular}

$* \mathrm{p}<0.10, * * \mathrm{p}<0.05$ and $* * * \mathrm{p}<0.01$.

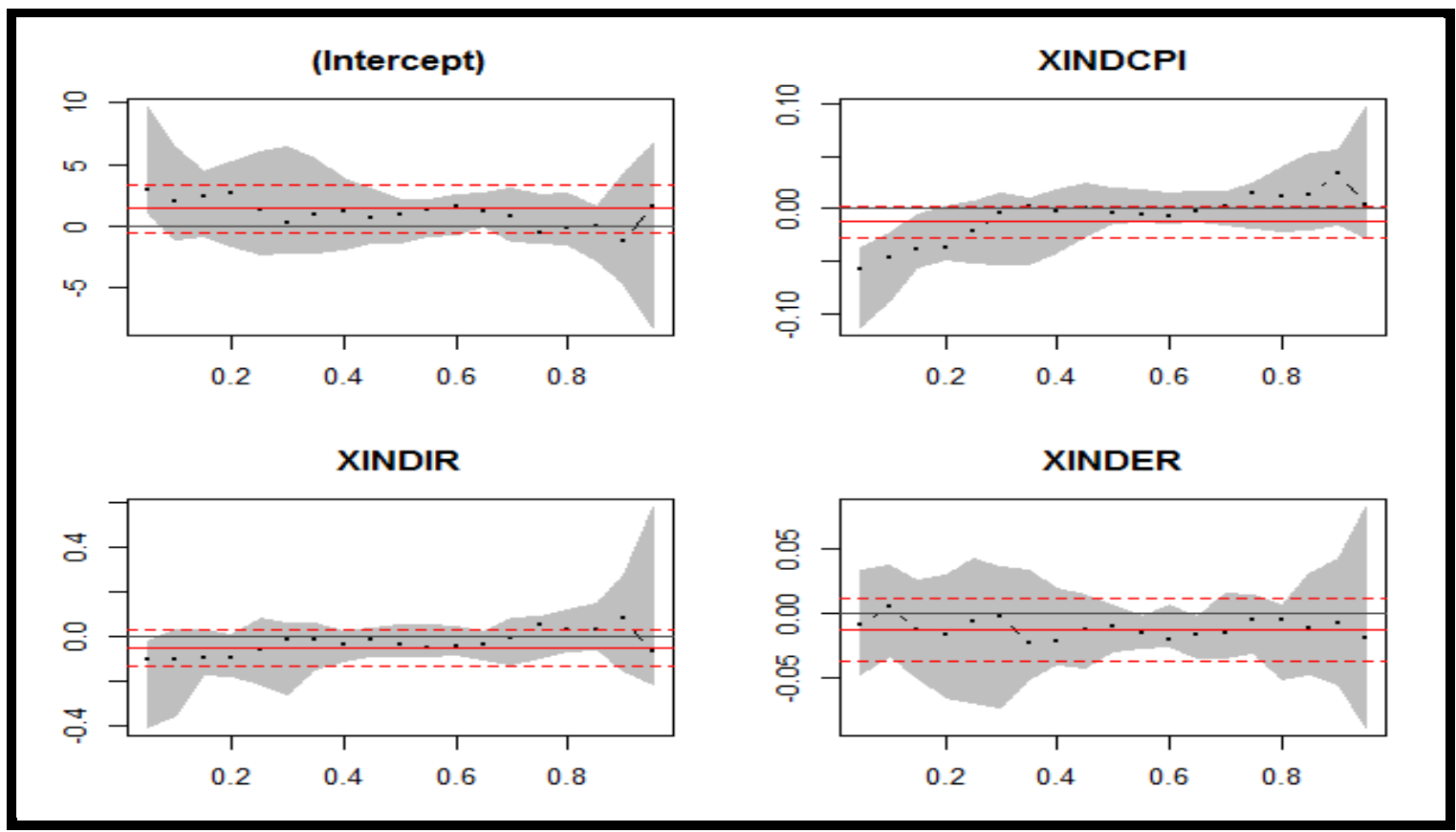

Figure 2. Alteration in QR coefficients for SSE during 1998-2008 


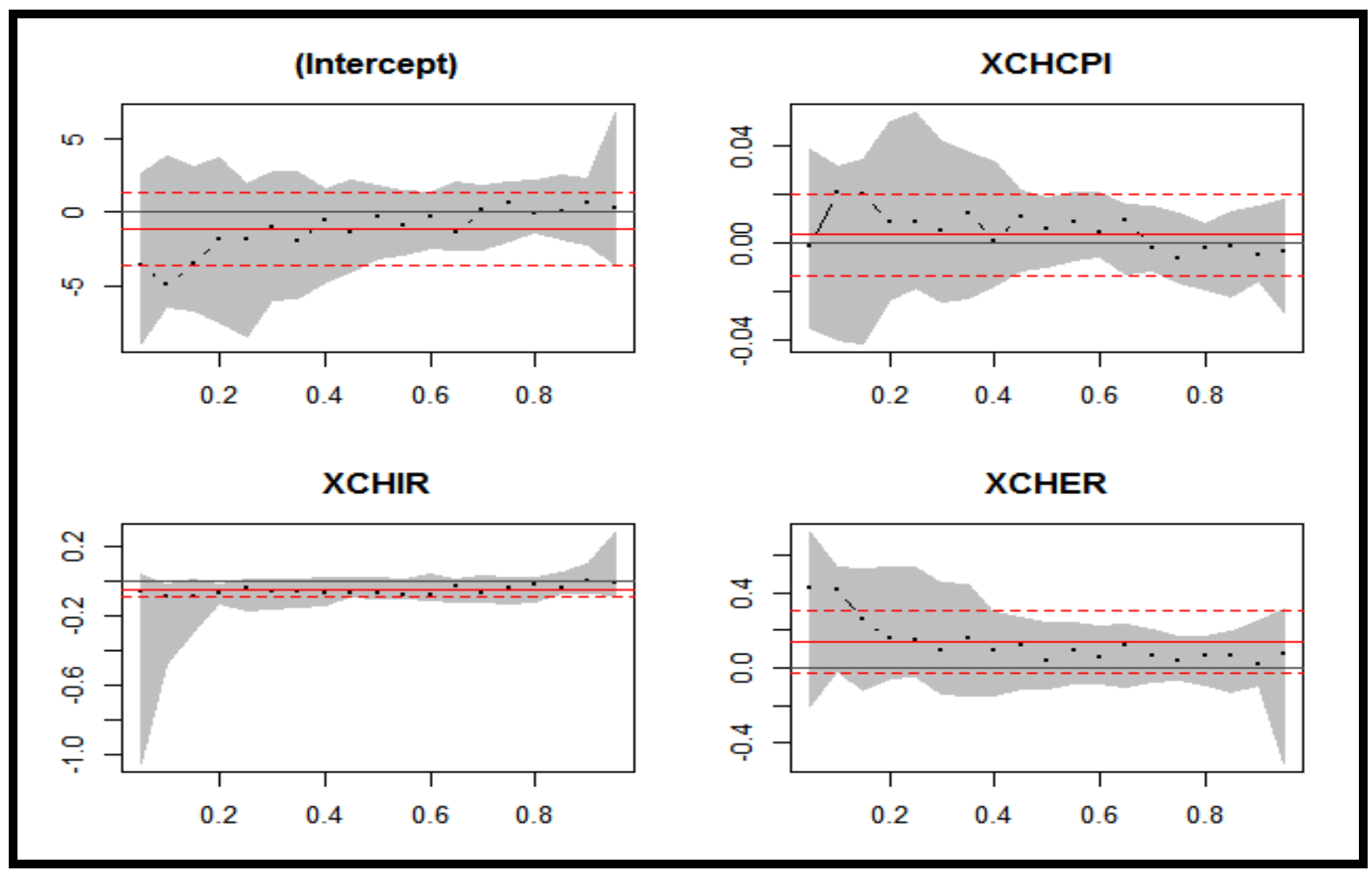

Figure 3. Alteration in QR coefficients for Nifty during 1998-2008

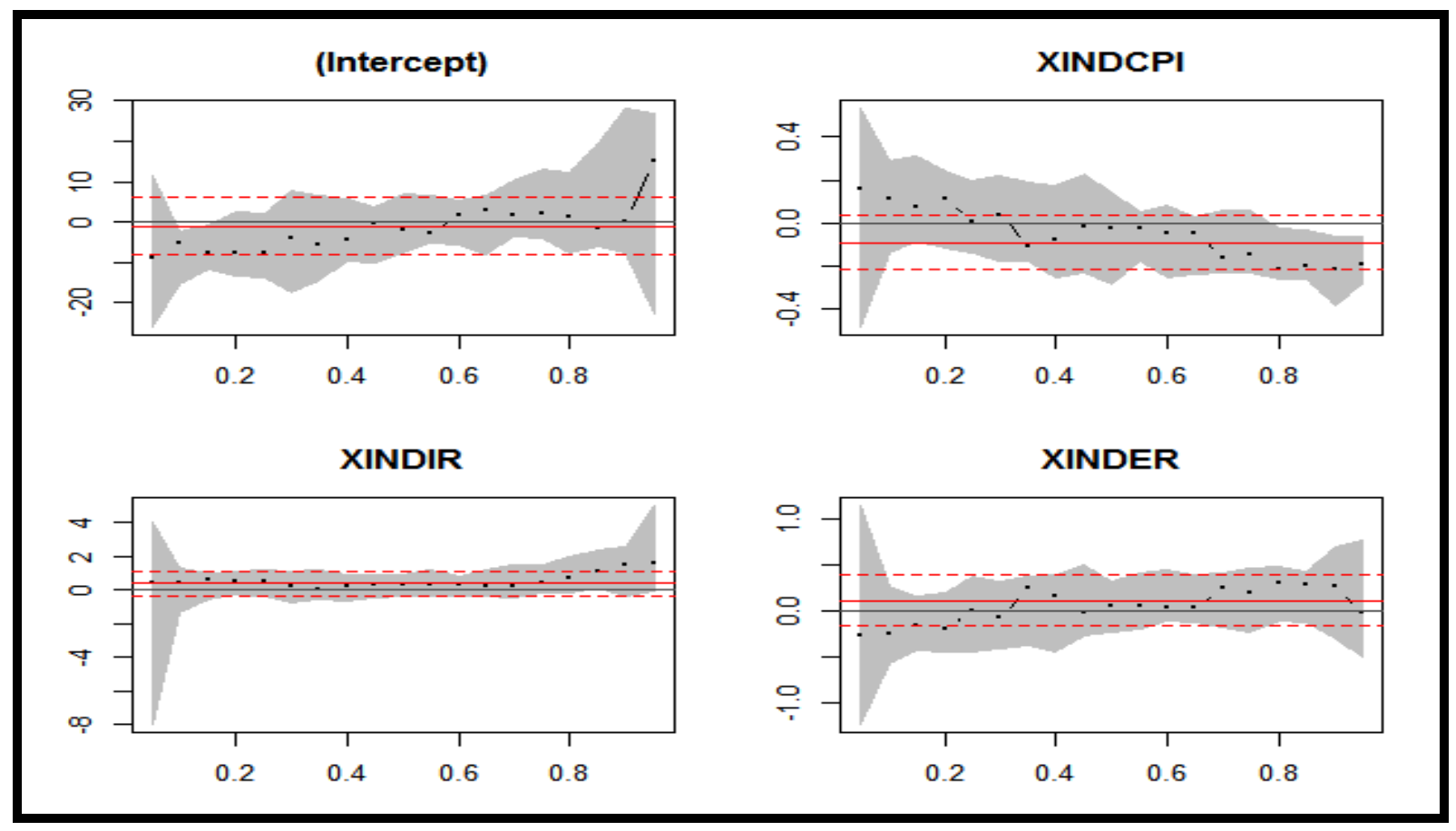

Figure 4. Alteration in QR coefficients for SSE during 2009-2018 


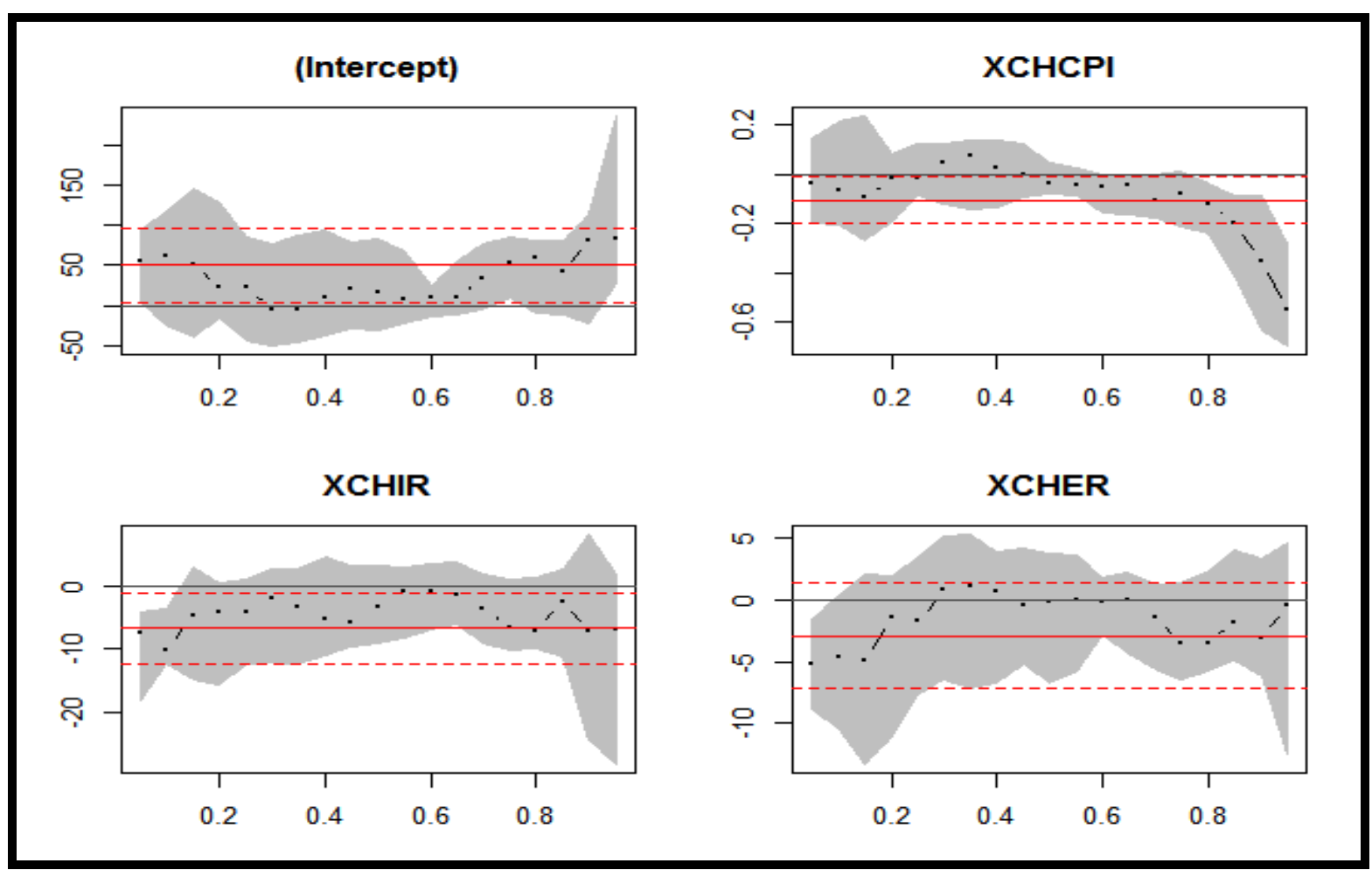

Figure 5. Alteration in QR coefficients for Nifty during 2009-2018

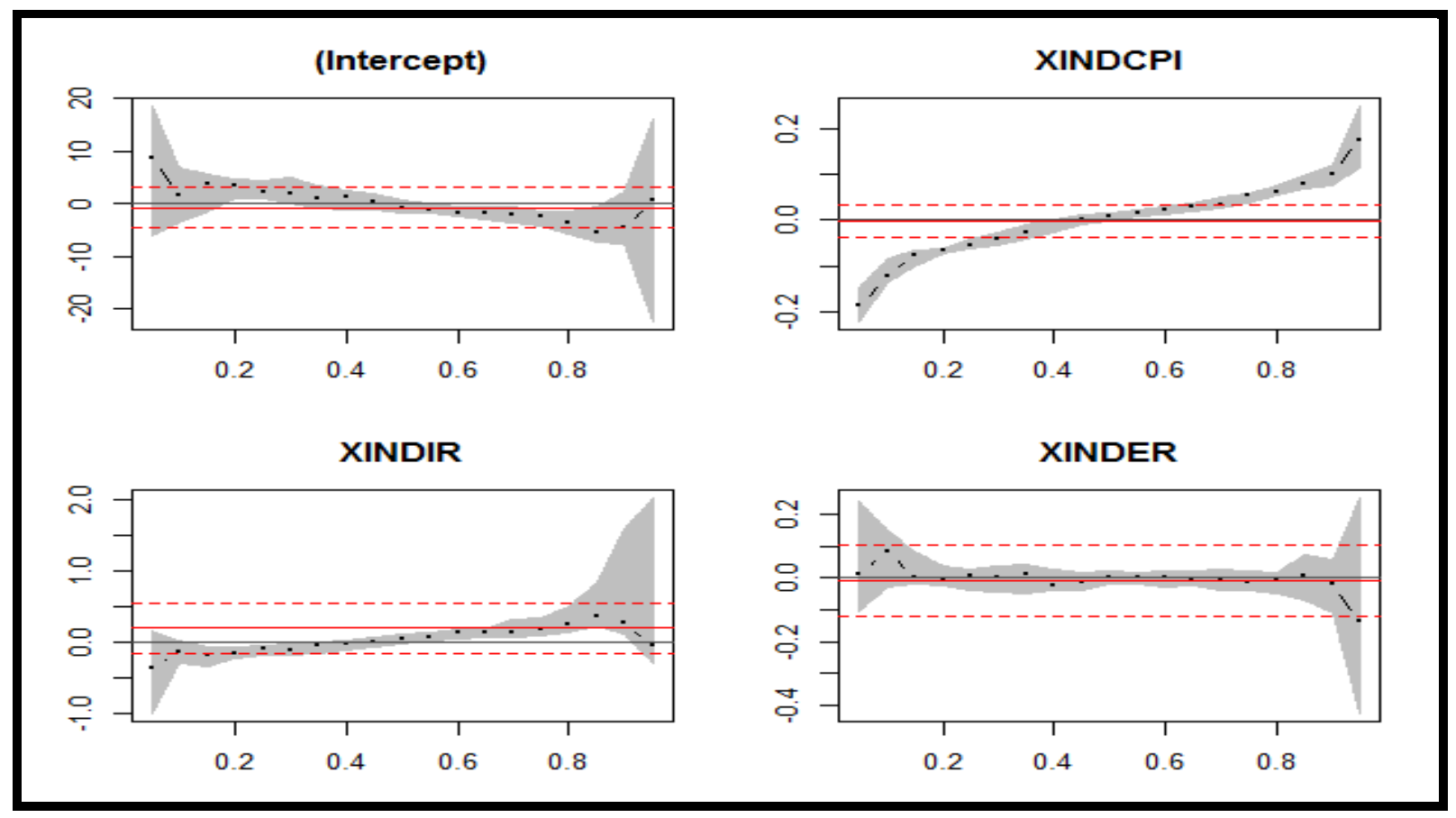

Figure 6. Alteration in QR coefficients for SSE during 1998-2018 


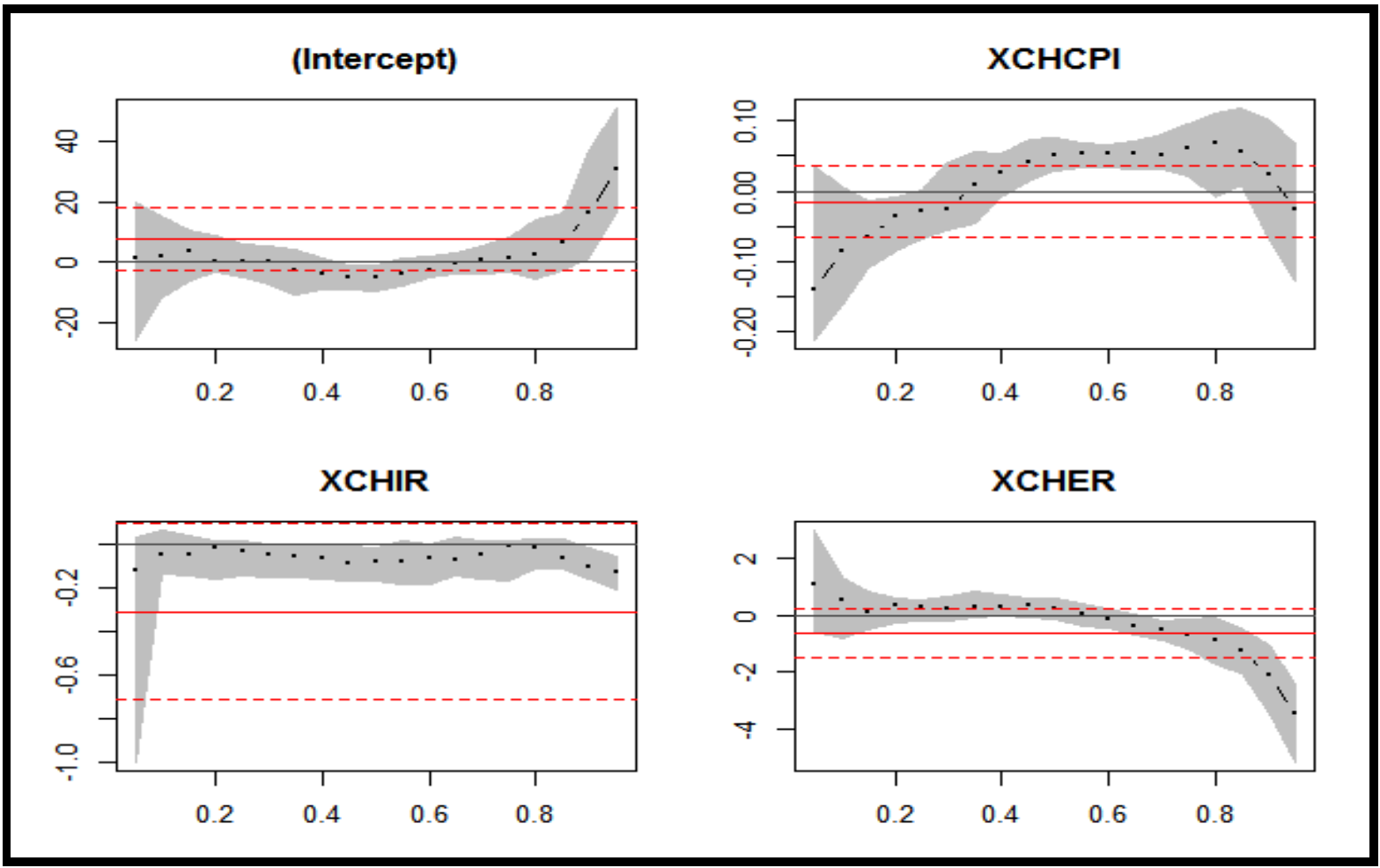

Figure 7. Alteration in QR coefficients for Nifty during 1998-2018

\section{Empirical Results}

This section describes the QR results for the SSE and Nifty returns during 1998-2008 and 2009-2018. The results also cover the entire 1998-2018 period. We estimate the SSE returns with Equation (3) employing the QR method (Table 2, Table 4, and Table 6). Moreover, we estimate Nifty returns with Equation (4) using the QR method (Table 3, Table 5, and Table 7). The changes in the QR coefficients for SSE and Nifty are also shown in the QR graph. The prefix ' $X$ ' indicates an explanatory variable.

\subsection{Dependence Structure Between Indian Macroeconomic Factors and SSE Returns}

The results for the 1998 to 2008 time period are noticed in Table 2 and Figure 2. CPI has a significant and negative impact on SSE returns for the lower quantiles. However, the quantile estimated coefficients for the intermediate and upper quantiles are insignificant. Thus, the impact is absent for the intermediate and upper quantiles. In the case of IR and ER, all the quantile estimated coefficients found to be insignificant for lower, intermediate, and upper quantiles. Therefore, IR and ER do not affect the SSE returns.

We observe the results for post-recession in Table 4 and Figure 4. We find a significant and negative impact of CPI on SSE returns for the 0.7 and 0.8 quantiles. But there is no impact for lower, intermediate, and 0.9 quantiles. An insignificant impact of IR and ER is noted on SSE returns across the quantiles.

It is important to note that the dependence structure between CPI and SSE returns shows a negligible change post-recession period. However, the dependence structure between IR, ER, and SSE returns has not changed after the recession.

Our results for the entire period shown in Table 6 and Figure 6 indicate that CPI has a significant and negative impact on SSE returns for the lower quantile. Moreover, CPI has a significant and but positive impact for the upper quantiles. However, the impact is absent for intermediate quantiles. IR and ER have no impact on SSE returns from 1998-2018.

\subsection{Dependence Structure Between Chinese Macroeconomic Factors and Nifty Returns}

The QR results for the pre-recession and recession period that is 1998-2008 presented in Table 3 and Figure 3 show that CPI does not influence Nifty returns because insignificant coefficients are found across the quantiles. However, IR has a significant and negative impact on Nifty returns at the $0.5,0.6$, and 0.7 quantiles. When the quantile regression is 
evaluated for the lower, $0.4,0.8$, and 0.9 quantiles, the IR has an insignificant influence on the Nifty returns. Regarding $\mathrm{ER}$, the impact is insignificant except 0.1 quantile.

For 2009- 2018, CPI affects the Nifty returns only for the 0.7 and 0.9 quantiles. But the impact is not observed for the lower, intermediate, and 0.8 quantiles. It is interesting to note an insignificant impact of IR and ER on Nifty returns (Table 5 and Figure 5).

We observe a significantly small change in the dependence structure between Chinese macroeconomic variables and Nifty returns post-recession.

The impact of Chinese macroeconomic factors on the Nifty for the entire period is also analysed in Table 7 and Figure 7. CPI has a significant and positive impact for the median, 0.6, 0.7, and 0.8 quantiles. However, the quantile estimated coefficients for the lower, 0.4, and 0.9 quantiles indicate an insignificant impact of CPI on Nifty returns. Further, IR does not influence Nifty returns because all the quantile estimated coefficients are insignificant. Nifty is influenced negatively by ER for the upper quantile only. But the impact is absent for the lower and intermediate quantiles.

\section{Conclusion and Recommendations}

\subsection{Conclusion}

Since China and India are the two fastest-growing emerging economies in the world, it becomes necessary to study the linkages and dependencies between the stock markets of these two countries. In addition to the existing literature on stock market linkages and dependencies, this paper contributes itself differently by applying QR methodology. Our paper provides new grounds for the interlinkages between Chinese and Indian stock markets. The results on the basis of the entire time period unveil that the impact of Chinese CPI and ER on Nifty is not uniform across the different quantiles. However, IR has no effect on Nifty returns. With regards to SSE returns, Indian CPI has a negligible influence on SSE returns. In contrast, IR and ER do not affect SSE returns.

It is significant to note that this paper uses QR methodology to address this issue. The limitation of this research is that this paper does not consider the stock markets other than China and India to study the linkages and dependencies between them. However, this study can be further extended to other macroeconomic variables. Another possible extension is to investigate the impact of macroeconomic factors of developed or emerging economies on China and India.

\subsection{Recommendations}

On the basis of the analysis of the entire time period, we find strong evidence that the SSE returns are sensitive to Indian CPI. Therefore, if investors want to earn returns and reduce risk created by macroeconomic factors, they should cautiously invest in the Chinese stock market considering Indian CPI. On the other hand, SSE returns are not sensitive to Indian IR and ER. Thus, investors should avoid investing in the Chinese stock market using these variables.

Further, Nifty returns react to Chinese CPI and ER. Therefore, investors are advised to monitor these two variables carefully to reap better returns. Alternatively, Nifty returns are not sensitive to Chinese IR.

\section{References}

Aldrick, P. (2019). India set to be world's fourth-biggest economy. The Times. Retrieved from https://www.thetimes.co.uk/article/india-set-to-be-world-s-4th-biggest-economy-73236s50z

Allen, D. E., Singh, A. K., \& Powell, R. (2013). Analysing the return distributions of Australian stocks: the CAPM, factor models and quantile regressions. Global Business and Economics Review, 15(1), 88-109. https://doi.org/10.1504/GBER.2013.050670

Alshammari, T. (2020). Integration of the GCC Stock Markets. Research in World Economy, 11(5), 24. https://doi.org/10.5430/rwe.v11n5p24

Bhattacharyya, S., Khan, G. S., Kundu, A., \& Saha, M. (2017). Global Financial Crisis, Foreign Portfolio Investment and Volatility: Impact Analysis on Select Southeast Asian Markets. Finance India, 31(4), 1191-1210.

Brooks, C. (2014). Introductory Econometrics for Finance. Cambridge, UK: Cambridge University Press.

Buchinsky, M. (1995). Estimating the asymptotic covariance matrix for quantile regression models a Monte Carlo study. Journal of Econometrics, 68(2), 303-338. https://doi.org/10.1016/0304-4076(94)01652-G

Bussière, M., \& Mehl, A. (2008). China's and India's roles in global trade and finance: Twin titans for the new millennium?. European Central Bank Occasional Paper Series, No. 80.

Chen, M. H. (2007). Macro and non-macro explanatory factors of Chinese hotel stock returns. International Journal of 
Hospitality Management, 26(4), 991-1004. https://doi.org/10.1016/j.ijhm.2006.04.002

Daboussi, O. M., \& Majoul, A. (2014). The transmission effects of the subprime crisis to emerging markets : A global VAR analysis. Asian Journal of Empirical Research, 4(9), 427-438.

Das, A., \& Megaravalli, A. V. (2017). Macroeconomic Indicators and Stock Market Boogie: The Case of National Stock Exchange, India. Indian Journal of Research in Capital Markets, 4(3), 20-32. https://doi.org/10.17010/ijrcm/2017/v4/i3/118913

Dasgupta, R. (2014). Integration and dynamic linkages of the Indian stock market with BRIC: An empirical study. Asian Economic and Financial Review, 4(6), 715-731.

Faniband, M. M., \& Marulkar, K. V. (2020). Quarterly Results and Share Prices: What Happens on the Date of Earnings Announcement?. Finance India, 34(1), 153-162.

Hosseini, S. M., Ahmad, Z., \& Lai, Y. W. (2011). The Role of Macroeconomic Variables on Stock Market Index in China and India. International Journal of Economics and Finance, 3(6), 233-243. https://doi.org/10.5539/ijef.v3n6p233

Jareño, F., Ferrer, R., \& Miroslavova, S. (2016). US stock market sensitivity to interest and inflation rates: a quantile regression approach. Applied Economics, 48(26), 2469-2481. https://doi.org/10.1080/00036846.2015.1122735

Jarrett, J. E., Klein, A. F., \& Kyper, E. (2013). Association between Asian Equity Markets and Western Markets: Evidence from the Indexes of Equity Markets. Asian Journal of Empirical Research, 3(8), 972-989.

Johansson, A. C. (2010). China's financial market integration with the world. Journal of Chinese Economic and Business Studies, 8(3), 293-314. https://doi.org/10.1080/14765284.2010.493642

Kaur, P., \& Arora, H. (2018). Financial markets interdependence in India: an empirical analysis. International Journal of Economics and Business Research, 16(4), 517-533. https://doi.org/10.1504/IJEBR.2018.095349

Koenker, R., \& Bassett, G. (1978). Regression Quantiles. Econometrica, 46(1), 33-50.

Lao, P., \& Singh, H. (2011). Herding behaviour in the Chinese and Indian stock markets. Journal of Asian Economics, 22(6), 495-506. https://doi.org/10.1016/j.asieco.2011.08.001

Mishra, H., \& Debasish, S. S. (2019). The quantile dependence between global crude oil price and stock markets in emerging Asia: evidence from major oil consuming nations. Afro-Asian Journal of Finance and Accounting, 9(3), 309-331. https://doi.org/10.1504/AAJFA.2019.100980

Ni, Z. X., Wang, D. Z., \& Xue, W. J. (2015). Investor sentiment and its nonlinear effect on stock returns-New evidence from the Chinese stock market based on panel quantile regression model. Economic Modelling, 50, 266-274. https://doi.org/10.1016/j.econmod.2015.07.007

Pal, K., \& Mittal, R. (2011). Impact of macroeconomic indicators on Indian capital markets. Journal of Risk Finance, 12(2), 84-97. https://doi.org/10.1108/15265941111112811

Panda, P., \& Thiripalraju, M. (2020). Stock Markets, Macroeconomics and Financial Structure of BRICS Countries and USA. Prajnan, 49(2), 123-159.

Pani, S. K., Bhatt, R., \& Himatsingka, G. (2019). The Effects of Economic and Political Events on the Movements of BSE Sensex: A Study of Outliers from 1991 to 2014. Finance India, 33(2), 407-422.

Patel, R. J. (2017). Co-Movement and Integration Among Stock Markets : A Study of 14 Countries. Indian Journal of Finance, 11(9), 53-66.

Sengupta, S., Dutta, A., \& Dutta, A. (2019). An Empirical Study of the effect of Macro- Economic Factors on the Stock Market: An Indian Perspective. Finance India, 33(1), 113-134.

Sharma, G. D., Mahendru, M., \& Singh, S. (2013). Are the Stock Exchanges of Emerging Economies Interlinked?: Evidence from BRICS. Indian Journal of Finance, 7(1), 26-37.

Singhania, K., \& Girish, G. P. (2015). Impact of Macroeconomic Events on Shanghai Stock Exchange. Asian Journal of Empirical Research, 5(6), 64-76. https://doi.org/10.18488/journal.1007/2015.5.6/1007.6.64.76

Tsai, I. C. (2012). The relationship between stock price index and exchange rate in Asian markets: A quantile regression approach. Journal of International Financial Markets, Institutions and Money, 22(3), 609-621. https://doi.org/10.1016/j.intfin.2012.04.005

Wang, Y. H., Hung, J. C., Kao, H. H., \& Shih, K. H. (2011). Long-term relationship between political behavior and 
stock market return: New evidence from quantile regression. Quality and Quantity, 45(6), 1361-1367. https://doi.org/10.1007/s11135-010-9340-x

Yang, H., Cheng, X., Huang, Q., \& Wang, Q. (2019). Systemic risk in the Chinese stock market under different regimes: A sector-level perspective. Asian Economic and Financial Review, 9(6), 665-679. https://doi.org/10.18488/journal.aefr.2019.96.665.679

Ye, G. L. (2014). The interactions between China and US stock markets: New perspectives. Journal of International Financial Markets, Institutions and Money, 31(1), 331-342. https://doi.org/10.1016/j.intfin.2014.04.008

Zhu, H., Guo, Y., You, W., \& Xu, Y. (2016). The heterogeneity dependence between crude oil price changes and industry stock market returns in China: Evidence from a quantile regression approach. Energy Economics, 55, 30-41. https://doi.org/10.1016/j.eneco.2015.12.027

\section{Copyrights}

Copyright for this article is retained by the author(s), with first publication rights granted to the journal.

This is an open-access article distributed under the terms and conditions of the Creative Commons Attribution license (http://creativecommons.org/licenses/by/4.0/). 